\title{
Exploring the relationship between urbanization and water environment based on coupling analysis in Nanjing, East China
}

\author{
Xiaoxue $\mathrm{Ma}^{1}$ (D) $\cdot$ Nimuzi $\mathrm{Li}^{1} \cdot$ Hong Yang ${ }^{2,3} \cdot$ Yanyan $\mathrm{Li}^{1}$ \\ Received: 20 January 2021 / Accepted: 23 June 2021 / Published online: 19 August 2021 \\ (C) The Author(s), under exclusive licence to Springer-Verlag GmbH Germany, part of Springer Nature 2021
}

\begin{abstract}
The degradation of water environment (WE) has constrained the sustainable development of cities, while the rapid urbanization also exacerbates water environment change. However, the complicated relationship between urbanization and WE is far from clearly understood. In this study, a comprehensive index system for urbanization and WE was applied along with the System Index Evaluation Model (SIEM) and a Coupling Coordination Degree Model (CCDM) to analyze the coupling between urbanization and WE in Nanjing, East China, from 1990 to 2018. The comprehensive index of urbanization increased from 0.0392 in 1990 to 0.9890 in 2018, showing a clear increasing trend. Demographic and spatial urbanization made the largest contribution to urbanization development from 1990 to 2010, while economic urbanization became the largest contributor to urbanization development between 2011 and 2018. Under the combined effects of pressure, state, and response subsystems, the comprehensive WE index showed an upward trend with some fluctuations from 1990 to 2018. The degree of coupling coordination between urbanization and WE displayed an overall upward tendency, growing from 0.18 in 1990 to 0.95 in 2018. The coupling coordination state transitioned from a serious imbalance during the low coupling period (1990-1992) into the superior coordination of the highly coupled period (2011-2018). With the continuous urbanization in the future, in addition to ensuring the optimal management of surface water, protection of groundwater should be reinforced. The results advance our understanding of the dynamic relationship between urbanization and WE and provide important implications for urban planning and water resource protection.
\end{abstract}

Keywords Urbanization $\cdot$ Water environment $\cdot$ Coupling coordination degree $\cdot$ Temporal variation

Responsible Editor: Ilhan Ozturk

Xiaoxue Ma

maxiaoxue029@126.com

Hong Yang

hongyanghy@gmail.com; h.yang4@reading.ac.uk

1 College of Urban and Environmental Sciences, Jiangsu Second Normal University, Nanjing 210013, China

2 Collaborative Innovation Center of Atmospheric Environment and Equipment Technology, Jiangsu Key Laboratory of Atmospheric Environment Monitoring and Pollution Control (AEMPC), School of Environmental Science and Engineering, Nanjing University of Information Science and Technology, Nanjing 210044, China

3 Department of Geography and Environmental Science, University of Reading, Reading RG6 6AB, UK

\section{Introduction}

The global urban population increased by approximately 3.6 billion from 1950 to 2018 , and it is predicted another 2.3 billion increase by 2050 (UN 2018). China has accounted for around $22 \%$ of the growth of world's urban population in the past seven decades, which far exceeds other countries (UN 2018). China will contribute around $10 \%$ of the projected growth of the world's urban population in the next 30 years (UN 2018). Urbanization, in general, brings economic development and population increase, but also with the consequence of eco-environment degradation (Fang et al. 2019). Some empirical studies show the complex interactive relationship between urbanization and the eco-environment (Conrad and Cassar 2014; Liu et al. 2020; Tchakonte et al. 2015). In the last decade, coupling has received growing attention for researching the interactive relationship between urbanization and eco-environment. Coupling refers to the phenomenon by which two or more systems or movement forms influence one 
another through various interaction mechanisms $(\mathrm{Li}$ et al. 2012). For example, the Remote Sensing Ecological Index (including wetness index, normalized vegetation index, nighttime light index, normalized differential build-up, and bare soil index) was applied to determine the coupling degree between urbanization and the eco-environment in Yanqi Basin, West China, and the results indicated moderately imbalanced coupling in the area (Ariken et al. 2020). The coupling degree between urbanization and the eco-environment in 13 cities in the Beijing-Tianjin-Hebei region was also not high, while it was on the rising trend (Cui et al. 2019). Thankfully, the coupling coordination degree between economic urbanization and eco-environmental indicators was relatively higher in Shanghai, the largest city in China (He et al. 2017). The published results indicate the various coupling relationship between urbanization and eco-environment across different areas (Srinivasan et al. 2013; Yao et al. 2019).

As an important part of the eco-environmental, water subsystems closely related to the process of urbanization (Juma et al. 2014). It has been found that urban populations are positively associated with water resource utilization, and a $1 \%$ increase in the urban population leads to a $0.925 \%$ increase in total water resource utilization (Wang 2020). Meanwhile, millions of people have migrated from rural to urban areas, while urban residential areas have sprawled much quicker than the population (He et al. 2017; Liu et al. 2014). The construction sector has accounted for about $30 \%$ of global freshwater consumption, and China's new construction area contributed almost half of the newly built floor area globally in the recent years (Hong et al. 2019; Yang et al. 2017). It is predicted that half of the world's population will be living in water-stressed areas by 2025 (WHO 2019). Along with growing consumption of water resource, urbanization will lead to an increase in wastewater discharge. For example, approximately 2.5 billion people worldwide are estimated to be affected by organic pollution, from wastewater and other sources, by 2050 (Wen et al. 2017). Therefore, serious challenges have become apparent for global water resources in relation to the rapid urbanization. However, the coupling between urbanization and water environment (WE) has received limited attention (Ma et al. 2016; Zhang et al. 2019a, b).

Some scholars have studied the impact of urbanization on WE, while the conclusions are inconsistent because of the differences in WE measurement indicators, research temporal scale, and spatial scale. In general, there are two main viewpoints on the impacts of urbanization on WE. The first viewpoint suggests that urbanization has positive effects on WE. Comprehensive water management practices (particularly wastewater treatment to reduce Chemical Oxygen Demand (COD), Biochemical Oxygen Demand (BOD), Total phosphorus (TP)), green infrastructure, and public services (e.g., rainwater harvesting, green roofs, and waste recycling) can improve water quality and water use efficiency, as well as the utilization of urban rainwater resources (Bao and Chen 2015; Bao and Zou 2017; Ma et al. 2016; Zhao et al. 2015). The second viewpoint argues that urbanization brings pressures on the WE mainly through degrading water quality and disturbing urban hydrology. Specifically, urbanization can trigger some water environmental problems, such as malodorous black, eutrophication, and loss of the biodiversity of aquatic species (Huang et al. 2018a; Huang et al. 2018b; Luo et al. 2018; Yang et al. 2018). The increase in urban impervious surfaces also alter the surface runoff, peak discharge, storm water frequencies, and groundwater recharge (Hou et al. 2020; Huang et al. 2020; Locatelli et al. 2017; Zhang et al. 2019a, b).

On the other hand, water resources can constrain the urbanization process (Bao and Zou 2017; Fang et al. 2007). Water resource is the foundation of the formation and development of cites. Not only are water resources required to meet the daily needs of city-dwellers, but water is also indispensable for ensuring the sustainable operation of industry and agriculture (Rasul and Sharma 2016; Xu et al. 2016; Zhang et al. 2019a, b). Worse, extreme water environment changes can threaten the sustainable development of urbanization and induce economic losses through water shortage, urban stormwater, and water pollution (Han et al. 2019a, b; Yang et al. 2012a, b; Zhang et al. 2019a, b). Thus, the relationship between urbanization and WE has become increasingly complicated. However, most of existing studies only illustrate the urbanization level using only a single parameter, such as land use and land cover change (LUCC), gross domestic product (GDP), population density, nighttime light, or urban sprawl (Eigenbrod et al. 2011; Li et al. 2016; Wang et al. 2019a, b), while the comprehensive socioeconomic development is far from clearly understood.

Despite growing studies on the relationship between urbanization and WE, to the best of our knowledge, the findings are constrained by at least two limitations. First, studies on the interactive relationship are mainly focused on "one-to-one" dual-element coupling effects, such as the coupling relationship between single urbanization parameter and single element like water quality (Fang et al. 2019), but few studies have explored the "many-to-one" and "many-to-many" coupling relationships and mechanisms. Second, most published results on the coupling degree between urbanization and the eco-environment mainly aim at the highly developed areas (i.e., Shanghai, Beijing in China) or typical arid area (i.e., Yanqi Basin, Ningxia) (Ariken et al. 2020; Cui et al. 2019; He et al. 2017; Lyu et al. 2018; Wang et al. 2014); little attention has been given to "new first-tier cities" which are experiencing the rapid urbanization.

To fill the knowledge gap, this study made the following attempts. Considering that population and economic 
development will accelerate the demand of land, space, and natural resources, the population-economy-social-spatial framework (PESS) was established to analyze the comprehensive urbanization development. To provide a quantitative basis for achieving harmonious relationships between humans and water systems, the pressure-state-response (PSR) framework (Wang et al. 2019a, b) was adopted to set up the evaluation index system for analyzing water resources, water environment, and water utilization. This study selected Nanjing, East China, as a representative of "new first-tier cities," because it has undergone rapid urbanization in the last decades. The main aims of the study are to (1) construct an urbanization quality index and water environment index based on the PESS and PSR, (2) analyze the dynamics of the indices of urbanization and the water environment from the perspectives of the whole system and subsystem in Nanjing from 1990 to 2018, and (3) explore the dynamic coupling process between urbanization and the water environment using a Coupling Coordination Degree Model (CCDM).

\section{Study area and methods}

\section{Study area}

Nanjing $\left(31^{\circ} 14^{\prime \prime} \mathrm{N}-32^{\circ} 37^{\prime \prime} \mathrm{N}, 118^{\circ} 22^{\prime \prime} \mathrm{E}-119^{\circ} 14^{\prime \prime}\right.$

E) is the capital of Jiangsu Province, East China, which is located in the lower reaches of the Yangtze River, and covers an area of $6597 \mathrm{~km}^{2}$ (Fig. 1). It lies in a subtropical monsoon climate area, with distinct four seasons. The annual average precipitation is $1236 \mathrm{~mm}$ from 2009 to 2018. In addition to being a famous tourist destination for its long history, Nanjing is an important economic node at the strategic intersection of the eastern coastal economic belt and the Yangtze River economic belt in China. From 1990 to 2018, the regional urbanization rate increased from 47.07 to $82.5 \%$; the average annual growth rate of urbanization was $1.27 \%$, higher than the national growth rate of $1.18 \%$. In the meantime, Nanjing's annual economic growth rate was $16.74 \%$, higher than the national economic growth rate of $9 \%$. The rank of built-up area rose from $15^{\text {th }}$ to $10^{\text {th }}$ in China during the period.

Despite the economic boom, more challenges have arisen from the imbalance between rapid urbanization and water resource consumption (Ma et al. 2020). In 2018, Nanjing's water resource per capita was less than a quarter of the national average. In addition, water has been continuously polluted, and around $57.2 \%$ of the total monitoring sections were in Grade IV (moderately polluted) or above (heavily polluted) (Nanjing Ecological Environment Bureau 2018). With the rapid urbanization, it is an urgent challenge for realizing the coordinated development of urbanization and the WE.

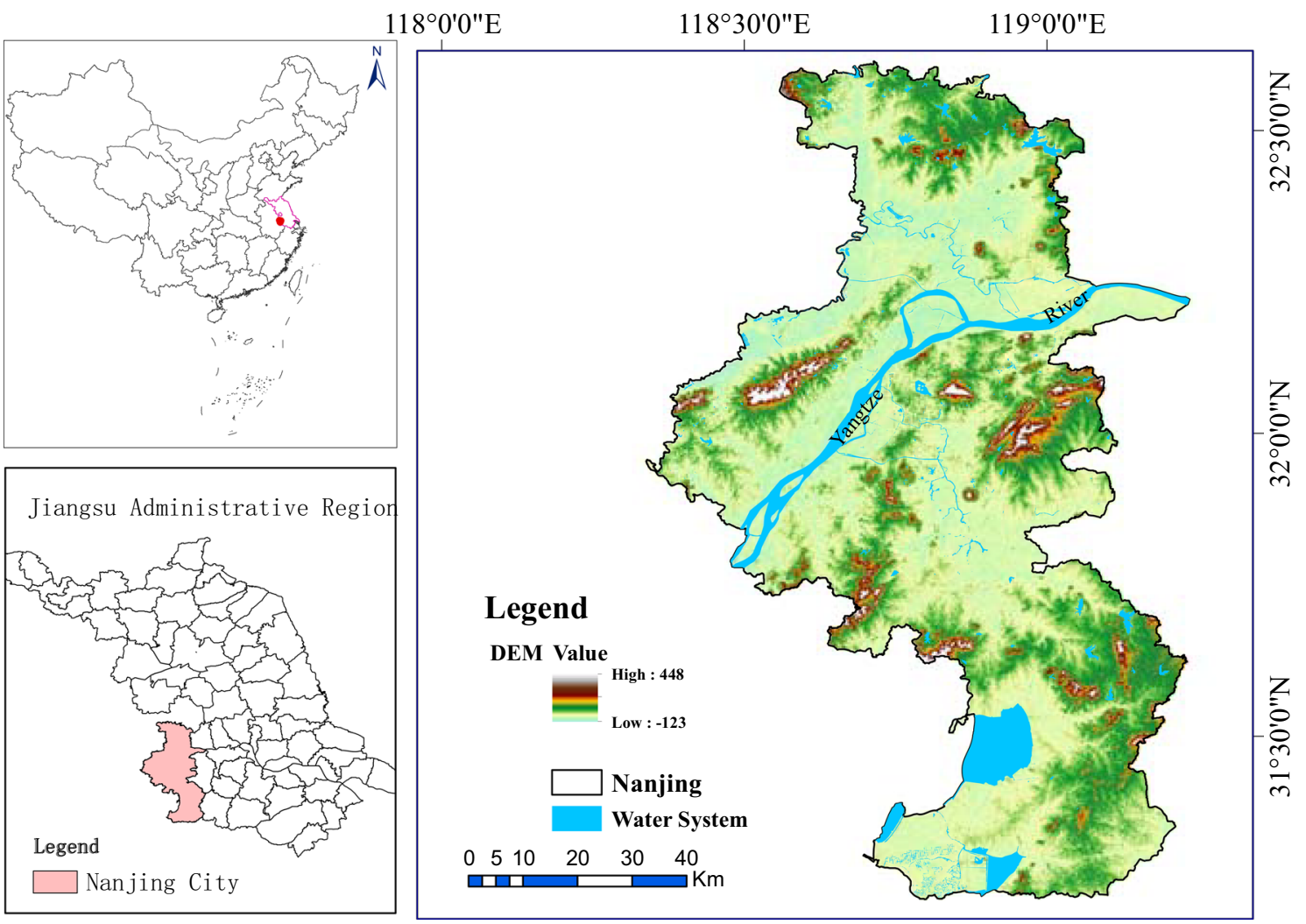

Fig. 1 The location and the digital elevation model (DEM) of the study area Nanjing City, East China 


\section{Methods}

\section{Index system design and data sources}

To explore the coupling relationship between urbanization and WE, this study first constructed an integrated indicator system to measure the urbanization process and WE. Indicators were selected based on the following criteria: (1) the most widely used indicators in the previous studies ( $\mathrm{He}$ et al. 2017; Liu et al. 2018a, b; Ren et al. 2014; Wang et al. 2014), (2) the indicators that are the components of urbanization process and also affect WE (Ma et al. 2016; Srinivasan et al. 2013), and (3) the simplest indicators that facilitate data collection, analyzing, and interpretation (Liu et al. 2011). In addition, the indicator selection considered experts' opinions and the local situation.

Water resource sustainability indicator framework has been constructed to study the sustainability of global water resources (Wada and Bierkens 2014) and region or watershed water resources in California (Shilling et al. 2013), northern India (Singhal et al. 2015), Peninsular Malaysia (Naubi 2017), and west Java (Juwana et al. 2010). However, there is still a lack of consensus not only on the conceptual framework, but also the approach. Pressure-state-response (PSR) model was introduced by the Organization for Economic Co-operation and Development (OECD) and has been increasingly used in the environmental research (Neri et al. 2016). The PSR model includes a causality of "what happened, why, and how to deal with it" and has the characteristics of flexibility and comprehensiveness (Hambling et al. 2011). In this context, this model reflects the current state of the WE under the pressure, identifies the reasons for a change in the state, and examines the response measures that are taken to overcome the pressures (Han et al. 2019a, b; Wang et al. 2019a, b).

Based on these studies, this research further developed the indicators of WE. In total, three primary indicators (pressure, state, and response) and 14 secondary indicators of the WE system were constructed (Table 1). Firstly, urbanization pressure on the water environment come from water resource consumption of industry, agriculture and domestic sector, and water quality deterioration caused by wastewater discharge. As the main industrial water pollutant, chemical oxygen demand (COD) is widely considered as the indicator of water pollution in China. Thus, industrial wastewater discharge and discharge of COD, water consumption of industrial, agricultural, domestic sectors were considered in this study. Secondly, the state subsystem not only refers to the water resource state under the pressure but also the water quality state under the pressure. Therefore, different from many previous studies, both the surface water quality and groundwater quality were considered in this paper. In order to overcome water resource pressures, sewage treatment and discharge reduction were widely applied. Wastewater reuse can also alleviate the pressure on water resources, and therefore industrial water reuse rate was considered in this study.

Urbanization is a complex process including spatial morphological change, socio-economic development, and urban population expansion. Many scholars evaluated China's newtype urbanization from four aspects, namely, population urbanization, economic urbanization, spatial urbanization, and social urbanization (Liu et al. 2018a, b; Han et al. 2019a, b; Zhao et al. 2016; Zhou et al. 2018). Similarly, the current study followed this framework and constructed four primary indicators (Table 1). Considering local situation and the principles of comprehensiveness and objectivity, some secondary indices were considered in this study. Firstly, as urbanization progresses, the economic structure shifts from primary to secondary and tertiary industries. Thus, the proportion of tertiary industry of total GDP and the ratio of tertiary industry output value to second industry output value were accounted for the economic aspect in this study. Secondly, the future urbanization will focus on sustainable development and ecological protection. Spatial urbanization not only involves the increase of impervious surface such as roads and construction land, but also involves the increase of ecological land such as green space. Thus, public green area and green coverage rate were considered for spatial urbanization in this study. Thirdly, unemployment rate is an important index to measure the economic and social development. Thus, in addition to education, transportation, medical care, and domestic consumption, unemployment rate was considered to represent social life quality of urban residents in this study.

The socio-economic data, population data, and urban land area data were obtained from the China City Statistical Yearbook (1991-2019) (NBS 2019), the Nanjing Statistical Yearbook (1991-2019) (NMBS 2019b), and the Nanjing Statistical Bulletin (2007-2018) (NMBS 2019a). The WE data were collected from the Nanjing City Water Resources Bulletin (2000-2018) (NHWRM 2019) and the Nanjing Statistical Yearbook (1991-2019) (NMBS 2019b).

\section{Data standardization}

To eliminate the influence of dimension and magnitude on the evaluation results and make the indicators comparable, the data were standardized using Eqs. (1) and (2) (Han et al. 2019a, b; Ren et al. 2014).

Positive indicator : $X_{i j}^{\prime}=\frac{X_{i j}-\min X_{j}}{\max X_{j}-\min X_{j}}$

Negative indicator : $X_{i j}^{\prime}=\frac{\max X_{j}-X_{i j}}{\max X_{j}-\min X_{j}}$

where $i$ is the year, $j$ is the indicator, $X_{i j}$ and $X_{i j}$ are the original value and the normalized value, and $\max X_{i j}$ and 
Table 1 Index system for urbanization and water environment in Nanjing, East China

\begin{tabular}{|c|c|c|c|c|c|}
\hline Target layer & Primary indicators & Secondary indicators & Weight & Nature & Source \\
\hline \multirow[t]{18}{*}{ Urbanization (X) } & $\begin{array}{l}\text { Demographic } \\
\quad \text { urbanization }\left(\mathrm{X}_{1}\right)\end{array}$ & $\begin{array}{l}X_{11} \text { Percentage of urban population }(\%) \\
X_{12} \text { Percentage of tertiary industry employment }(\%)\end{array}$ & $\begin{array}{l}0.4380 \\
0.5620\end{array}$ & $\begin{array}{l}+ \\
+\end{array}$ & $\begin{array}{l}\text { Yu et al. (2018); Liu et al. } \\
\text { (2018b) }\end{array}$ \\
\hline & \multirow{5}{*}{$\begin{array}{l}\text { Economic urbanization } \\
\quad\left(\mathrm{X}_{2}\right)\end{array}$} & $\mathrm{X}_{21}$ GDP per capita (US\$) & 0.3203 & + & \multirow[t]{3}{*}{ Zhao et al. (2016) } \\
\hline & & $\mathrm{X}_{22}$ Industrial output value per capita (US\$) & 0.2642 & + & \\
\hline & & $\mathrm{X}_{23}$ Total fixed asset investment per capita (US\$) & 0.2959 & + & \\
\hline & & $\begin{array}{l}X_{24} \text { Tertiary industry output value as a percentage of GDP } \\
(\%)\end{array}$ & 0.0440 & + & \multirow[t]{2}{*}{ Designed by authors } \\
\hline & & $\begin{array}{l}\mathrm{X}_{25} \text { The ratio of tertiary industry output value to second } \\
\text { industry output value (\%) }\end{array}$ & 0.0756 & + & \\
\hline & \multirow{5}{*}{$\begin{array}{l}\text { Spatial urbanization } \\
\left(\mathrm{X}_{3}\right)\end{array}$} & $\mathrm{X}_{31}$ Urban population density (persons $/ \mathrm{km}^{2}$ ) & 0.1529 & - & Zhao et al. (2016) \\
\hline & & $\begin{array}{l}\mathrm{X}_{32} \text { Road area per capita }\left(\mathrm{m}^{2} / \text { person }\right) \\
\mathrm{X}_{33} \text { Total area of built-up area }\left(\mathrm{km}^{2}\right)\end{array}$ & $\begin{array}{l}0.2226 \\
0.2482\end{array}$ & $\begin{array}{l}+ \\
+\end{array}$ & \multirow[t]{2}{*}{ Han et al. $(2019 a, b)$} \\
\hline & & $\mathrm{X}_{34}$ Living area of urban residents per capita ( $\mathrm{m}^{2} /$ person) & 0.2255 & + & \\
\hline & & $\mathrm{X}_{35}$ Public green area per capita $\left(\mathrm{m}^{2}\right)$ & 0.1250 & + & \multirow[t]{2}{*}{ Designed by authors } \\
\hline & & $\mathrm{X}_{36}$ Green coverage rate in built-up area $(\%)$ & 0.0258 & + & \\
\hline & \multirow{7}{*}{$\begin{array}{l}\text { Social urbanization } \\
\qquad\left(\mathrm{X}_{4}\right)\end{array}$} & $\mathrm{X}_{41}$ Disposable income of urban residents per capita (US\$) & 0.2187 & + & \multirow{6}{*}{$\begin{array}{l}\text { Wang et al. (2014); } \\
\text { Yu et al. (2018); } \\
\text { Zhao et al. (2016) }\end{array}$} \\
\hline & & $\begin{array}{l}\mathrm{X}_{42} \text { Consumption expenditure of urban residents per capita } \\
\text { (US\$) }\end{array}$ & 0.1876 & + & \\
\hline & & $\mathrm{X}_{43}$ Social consumer good retail sales $\left(1.555^{*} 10^{7}\right.$ US\$ $)$ & 0.2612 & + & \\
\hline & & $\mathrm{X}_{44}$ Number of university students $\left(10^{4}\right.$ persons $)$ & 0.1674 & - & \\
\hline & & $\mathrm{X}_{45}$ Number of doctors per $10^{4}$ persons & 0.0287 & + & \\
\hline & & $\mathrm{X}_{46}$ Number of buses per $10^{4}$ persons & 0.0713 & + & \\
\hline & & $\mathrm{X}_{47}$ Urban registered unemployment rate (\%) & 0.0650 & + & Designed by authors \\
\hline \multirow{14}{*}{$\begin{array}{l}\text { Water } \\
\text { environment } \\
\text { (Y) }\end{array}$} & \multirow[t]{4}{*}{ WE pressure $\left(\mathrm{Y}_{1}\right)$} & $\mathrm{Y}_{11}$ Daily water consumption per capita (L/(per-d)) & 0.0779 & + & \multirow[t]{4}{*}{ Wang et al. $(2019 a, b)$} \\
\hline & & $\mathrm{Y}_{12}$ Industrial wastewater discharge $\left(10^{8} \mathrm{t}\right)$ & 0.1192 & + & \\
\hline & & $\begin{array}{l}Y_{13} \text { Water consumption per } 1555 \text { US\$ }\left(10^{4} \text { yuan }\right) \text { of GDP } \\
\left(\mathrm{m}^{3} / 1555 \text { US } \$\right)\end{array}$ & 0.3434 & + & \\
\hline & & $\begin{array}{l}Y_{14} \text { Water consumption per } 1555 \text { US\$ of industrial output } \\
\text { value }\left(\mathrm{m}^{3} / 1555 \text { US\$) }\right.\end{array}$ & 0.3141 & + & \\
\hline & \multirow[t]{7}{*}{ WE state $\left(\mathrm{Y}_{2}\right)$} & $\begin{array}{l}Y_{15} \text { Discharge of chemical oxygen demand (COD) in waste- } \\
\text { water }\left(10^{4} \mathrm{t}\right)\end{array}$ & 0.1243 & - & \multirow[t]{2}{*}{ Designed by authors } \\
\hline & & $\mathrm{Y}_{16}$ Agricultural water consumption $\left(10^{8} \mathrm{~m}^{3}\right)$ & 0.0211 & - & \\
\hline & & $\mathrm{Y}_{21}$ Water resources per capita (L/person) & 0.2869 & - & \multirow[t]{3}{*}{ Ji and $\mathrm{Ni}(2018)$} \\
\hline & & $\mathrm{Y}_{22}$ Annual rainfall $(\mathrm{mm})$ & 0.2076 & - & \\
\hline & & $\mathrm{Y}_{23}$ Total urban water supply $\left(10^{4} \mathrm{t}\right)$ & 0.0808 & - & \\
\hline & & $\begin{array}{l}Y_{24} \text { Rate of surface water quality up to water functional area } \\
\text { standard (\%) }\end{array}$ & 0.2550 & + & \multirow[t]{2}{*}{ Designed by authors } \\
\hline & & $\mathrm{Y}_{25}$ Rate of groundwater quality up to national standard (\%) & 0.2546 & + & \\
\hline & \multirow[t]{3}{*}{ WE response $\left(\mathrm{Y}_{3}\right)$} & $\mathrm{Y}_{31}$ Industrial wastewater discharge compliance rate $(\%)$ & 0.1515 & + & \multirow[t]{2}{*}{ Han et al. $(2019 a, b)$} \\
\hline & & $\mathrm{Y}_{32}$ Sewage treatment rate $(\%)$ & 0.4238 & + & \\
\hline & & $\mathrm{Y}_{33}$ Industrial water reuse rate $(\%)$ & 0.4247 & + & Designed by authors \\
\hline
\end{tabular}

Note: “+”: positive indicator; “-”: negative indicator

$\min X_{i j}$ represent the maximum and minimum values of the indicator $j$ over the research period.

\section{Determination of the weights of indicators}

Considering the complexity and uncertainty of the humanwater system, the entropy method was used to determine the weights of the control variables (Jia et al. 2018). The weights of indicators were calculated following the steps below:
Urbanization index weight : $w_{i}=\frac{V_{i}}{\sum_{i=1}^{n} V_{i}}$

Water environment index weight : $w_{j}=\frac{V_{j}}{\sum_{j=1}^{n} V_{j}}$

where $V_{i}$ and $V_{j}$ are the coefficients of variation of urbanization and $\mathrm{WE}$ assessment indicators, respectively. 
$V_{i}$ and $V_{j}$ were calculated as follows:

$V_{\mathrm{i}}=\frac{S_{\mathrm{i}}}{\overline{X_{\mathrm{i}}}}$ or $V_{j}=\frac{S_{j}}{\overline{X_{j}}}$

where $S_{i}$ and $S_{j}$ are the standard deviations, $\overline{X_{i}}$ and $\overline{X_{j}}$ is the average values of the $i$ or $j$ evaluation indicators of urbanization and WE, respectively.

\section{Coupling Coordination Degree Model (CCDM)}

Coupling is kind of phenomenon by which two or more systems or movement forms influence one another through various interaction mechanisms ( $\mathrm{Li}$ et al. 2012). Based on the concept of capacitive coupling and capacitive coupling coefficient model in physics (Illingworth 1996), the coupling degree $(C)$ was introduced by Liao (1999) to describe the degree of interactive influence between systems. However, in some cases, the degree of coupling alone cannot satisfactorily reflect the integrated coherence and synergistic effect of the system (Ai et al. 2016; Han et al. 2019a, b). Therefore, the Coupling Coordination Degree Model (CCDM) was developed to determine the sequence and structure of the system when it reached the critical region or to determine the trend that the system developed from disorder to order (Zhou et al. 2016; Liu et al. 2018a, b). The concept has been increasingly applied to further understand the relationship between urbanization and eco-environment (Han et al. 2019a, b; He et al. 2017; Li et al. 2012). In this study, the coupling relationship between urbanization and WE can be addressed as an effect-feedback framework among different systems (Liu et al. 2007), and the system that is composed of urbanization and WE subsystems can be defined as a coupling system in which the coupling relationship facilitates the realization of healthy urbanization (He et al. 2017).

The coupling degree $(C)$ and coupling coordination degree (D) between urbanization and WE were calculated as follows (Ding et al. 2015; Zhou et al. 2016):

The coupling coordination degree $: D=\sqrt{C T}$

The coupling degree : $C=\frac{f(\mathrm{x})^{k} g(\mathrm{y})^{k}}{T^{2 k}}$

Comprehensive evaluation index : $T=\alpha f(x)+\beta g(y)$

Comprehensive urbanization index $: f(x)=\sum_{i=1}^{m} w_{i} x_{i}$

Comprehensive WE index : $g(y)=\sum_{j=1}^{n} w_{j} y_{j}$

where $m$ is the number of urbanization indicators, $n$ is the number of water environmental indicators, $x_{i}$ and $y_{j}$ are the evaluation indicators for urbanization and water environmental systems, and $w_{i}$ and $w_{j}$ are their respective weights. $C$ indicates the extent of coupling between the subsystems. The larger the value of $C$, the greater the level of coordination between urbanization and the $\mathrm{WE}$, and the higher the coupling degree (Xiao et al. 2020). $D$ is the coupling coordination degree, an index to measure the coordination state between systems. The larger the value of $D$, the higher the coupling coordination degree, and the better coordination state of urbanization and the WE. $k$ is the adjustment coefficient, in the range of 2-5. Because there are only two systems (urbanization and WE) in this study, $\mathrm{k}=2 . \alpha$ and $\beta$ are undetermined coefficients. Because the two parameters $\alpha$ urbanization and $\beta$-WE have minimal effect on the coupling coordination system (He et al. 2017), this study considered that urbanization and the WE were in a mutually beneficial and restrictive relationship, and they were equally important $(\alpha=\beta=$ $0.5)$.

To better explain the degree of mutual coupling and coordinated development of urbanization and WE on the basis of comprehensive research classification, the coupling coordination degree can be divided into three primary development stages, which can be further divided into five secondary development stages (He et al. 2017; Huang et al. 2019; Liu et al. 2018a, b) (Table 2). Furthermore, nine tertiary development stages can be used to describe the coupling relationship between urbanization $(\mathrm{f}(\mathrm{x}))$ and WE $(\mathrm{g}(\mathrm{y}))$ (Table 2).

\section{Results}

\section{Temporal variation in the comprehensive urbanization index in Nanjing from 1990 to 2018}

The comprehensive evaluation index of urbanization was obtained by calculating the demographic, economic, spatial, and social urbanization indices from 1990 to 2018 (Fig. 2). The comprehensive index of urbanization increased from 0.0392 in 1990 to 0.9890 in 2018, showing a clear and steady upward trend. During the same period, the demographic, economic, spatial, and social urbanization indices all showed overall upward trends. According to the fluctuation ranges of different urbanization subsystem indices, the process can be divided into three stages: the first stage (1990-2000), the second stage (2001-2010), and the third stage (2011-2018). In the first stage (1990-2000), the urbanization subsystem index grew slowly, while the demographic urbanization index took the lead through rapid development, and its values were markedly higher than the other three urbanization indices. In the second stage (2001-2010), the growth rate of the urbanization index was substantially higher than those in the first phase at the subsystem levels and system level. In the first half of the stage, the spatial and demographic urbanization indices grew faster, while the economic and social urbanization indices grew quicker in the second half of the stage. During this stage, 
Table 2 Standards for identifying the coupling coordination between urbanization and water environment

\begin{tabular}{|c|c|c|c|c|}
\hline Primary division & $\begin{array}{l}\text { Coupling } \\
\text { coordination (D) }\end{array}$ & Secondary division & $\begin{array}{l}\text { Comparison between } \\
\mathrm{f}(\mathrm{x}) \text { and } \mathrm{g}(\mathrm{y})\end{array}$ & Tertiary division \\
\hline $\begin{array}{r}\text { Balanced development } \\
\text { (acceptable interval) }\end{array}$ & $\begin{array}{l}0.85<\mathrm{D} \leqq 1 \\
0.7<\mathrm{D} \leqq 0.85\end{array}$ & $\begin{array}{l}\text { Superiorly balanced } \\
\text { development } \\
\text { Coordinated } \\
\text { development }\end{array}$ & $\begin{array}{l}\mathrm{f}(\mathrm{x})>\mathrm{g}(\mathrm{y}) \\
\mathrm{f}(\mathrm{x})=\mathrm{g}(\mathrm{y}) \\
\mathrm{f}(\mathrm{x})<\mathrm{g}(\mathrm{y})\end{array}$ & $\begin{array}{l}\text { Superiorly balanced development with } \\
\text { environment lagging behind } \\
\text { Superiorly balanced development of } \\
\text { urbanization and environment } \\
\text { Superiorly balanced development with } \\
\text { urbanization lagging behind }\end{array}$ \\
\hline $\begin{array}{l}\text { Transitional development } \\
\text { (transitional interval) }\end{array}$ & $0.5<\mathrm{D} \leqq 0.7$ & $\begin{array}{c}\text { Barely coordinated } \\
\text { development }\end{array}$ & $\begin{array}{l}\mathrm{f}(\mathrm{x})>\mathrm{g}(\mathrm{y}) \\
\mathrm{f}(\mathrm{x})=\mathrm{g}(\mathrm{y}) \\
\mathrm{f}(\mathrm{x})<\mathrm{g}(\mathrm{y})\end{array}$ & $\begin{array}{l}\text { Superiorly balanced development with } \\
\text { environment lagging behind } \\
\text { Superiorly balanced development of } \\
\text { urbanization and environment } \\
\text { Superiorly balanced development with } \\
\text { urbanization lagging behind }\end{array}$ \\
\hline $\begin{array}{l}\text { Imbalanced development } \\
\text { (unacceptable interval) }\end{array}$ & $\begin{array}{l}0.25<\mathrm{D} \leqq 0.5 \\
0<\mathrm{D} \leqq 0.25\end{array}$ & $\begin{array}{l}\text { Slightly imbalanced } \\
\text { development } \\
\text { Severely imbalanced } \\
\text { development }\end{array}$ & $\begin{array}{l}\mathrm{f}(\mathrm{x})>\mathrm{g}(\mathrm{y}) \\
\mathrm{f}(\mathrm{x})=\mathrm{g}(\mathrm{y}) \\
\mathrm{f}(\mathrm{x})<\mathrm{g}(\mathrm{y})\end{array}$ & $\begin{array}{l}\text { Superiorly balanced development with } \\
\text { environment lagging behind } \\
\text { Superiorly balanced development of } \\
\text { urbanization and environment } \\
\text { Superiorly balanced development with } \\
\text { urbanization lagging behind }\end{array}$ \\
\hline
\end{tabular}

spatial urbanization and demographic urbanization had similar trends, while economic urbanization and social urbanization showed similar patterns. In the third stage (2011-2018), the economic urbanization index took the lead through the rapid growth. After 2014, the social urbanization index developed rapidly. Economic urbanization indices exceeded the demographic and space urbanization indices in 2014, while social urbanization indices surpassed the demographic and space urbanization indices in 2018.

\section{Temporal variation in the comprehensive WE index from 1990 to 2018}

According to the weights of all indicators in the WE system and the obtained data, the pressure, state, and response indices and the comprehensive WE index (the sum of pressure, state, and response) of Nanjing's WE from 1980 to 2018 were calculated (Fig. 3). The comprehensive WE index showed an upward trend with some fluctuations during the period. Among the three indices (pressure, state, and response), the WE state index demonstrated a slightly increasing pattern with some fluctuations. The WE pressure index and response index showed clear upward trends. From 1990 to 2000, the growth rate of the WE response indices was the largest, while the fluctuation of the WE pressure indices was the biggest. The WE pressure reached the maximum level in 1992. Although all three indices affected the comprehensive WE index, WE state is the main factor influencing the comprehensive level of WE system.
Fig. 2 The urbanization levels in Nanjing from 1990 to 2018

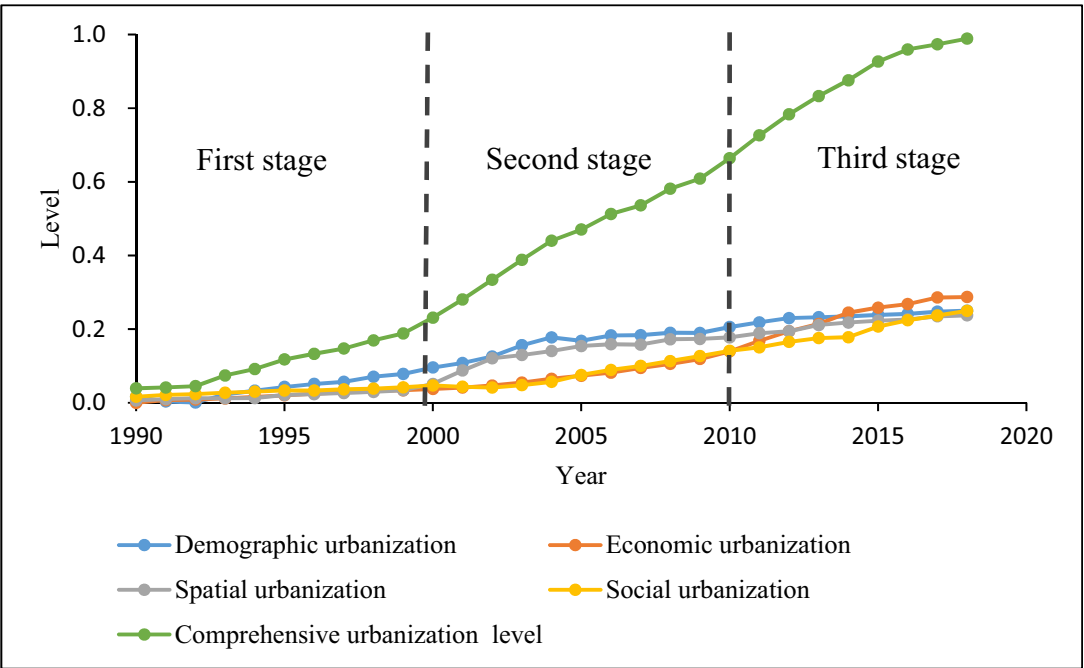




\section{Degree of coupling coordination between urbanization and WE}

The coupling coordination degree $(D)$ between urbanization and the WE demonstrated an overall rising trend with some fluctuations during the research period, growing from 0.18 in 1990 to 0.95 in 2018 (Fig. 4). In general, the coupling coordination state between urbanization and the WE system improved, advancing from the serious imbalance in 1990 to the highly coupled period in 2018. Based on the urbanization performance trend, the water ecosystem performance trend, and the coordination state, the change of the coupling system can be divided into two different stages: the first stage (19902010), the comprehensive urbanization index lagged behind the WE, and the second stage (2011-2018), the comprehensive WE index lagged behind the urbanization (Fig. 5). Further analysis are described as follows:

(1) 1990-2010: The first stage can be further divided into two periods. From 1990 to 1998, the comprehensive index gap between urbanization and WE gradually widened (Fig. 5). Its coupling coordination degree underwent a stage of imbalance. The coupling degree and coordination levels changed from a serious imbalance during the low coupling period (1990-1992) to a slightly imbalanced development during the antagonism period (1993-1999) (Fig. 4). On average, the comprehensive level of urbanization and WE was low during this period. From 2000 to 2010, the gap in the comprehensive index between urbanization and WE gradually narrowed (Fig. 5 ). The state of the coupling coordination between the two systems varied from the balanced development of the running-in period (2000-2003) to the coordination of the highly coupled period (2004-2010) (Fig. 4).

(2) 2011-2018: With the continued strengthening of water resources protection, the pressure on the water environment due to urbanization gradually decreased, and the conflict between urbanization and the WE gradually abated. During this phase, the urbanization subsystem and WE subsystem developed rapidly, which resulted in a higher comprehensive level of urbanization and WE (Fig. 5). The development of the two systems was in a superiorly coordinated state of the highly coupled phase (Fig. 4).

\section{Discussion}

\section{Assessment of the urbanization subsystems}

Similar to many cities in the world, Nanjing has experienced rapid urbanization in the last decades, while the temporal changes in the four subsystems of urbanization were different.

In the first phase (1990-2000), owing to the Asian financial crisis and the national policy of protecting cultivated land, Nanjing's GDP and land urbanization grew slowly (Lu et al. 2015; Wu et al. 2015). Spatial development mainly focused on the construction of small towns during this period in Jiangsu province where Nanjing is the capital. The development of roads, residential area, and other construction area slowly progressed, along with the slow economic development. However, due to the attraction of the economic development in central cities, the rural and suburban population continued to migrate to the urban area in this period.

In the second phase (2001-2010), the spatial urbanization primarily constructed the prefecture-level central cities in Jiangsu province, with implementing of police of compensable use of the state-owned land. Constructing the Nanjing metropolitan area was greatly promoted. Specifically, National Economic and Technological Development Zones, Export Processing Zones, and University Town (Jiangning and Xianlin) were constructed, which accelerated the process of spatial urbanization in Nanjing ( $\mathrm{Li}$ et al. 2018). In addition to spatial urbanization, population urbanization developed rapidly during this stage. Two factors promoted the growth of population urbanization: administrative division and population policy. There were two adjustments of administrative
Fig. 3 Trends of the three subsystems (state, pressure, and response) and the comprehensive levels of the water environment system in Nanjing from 1990 to 2018

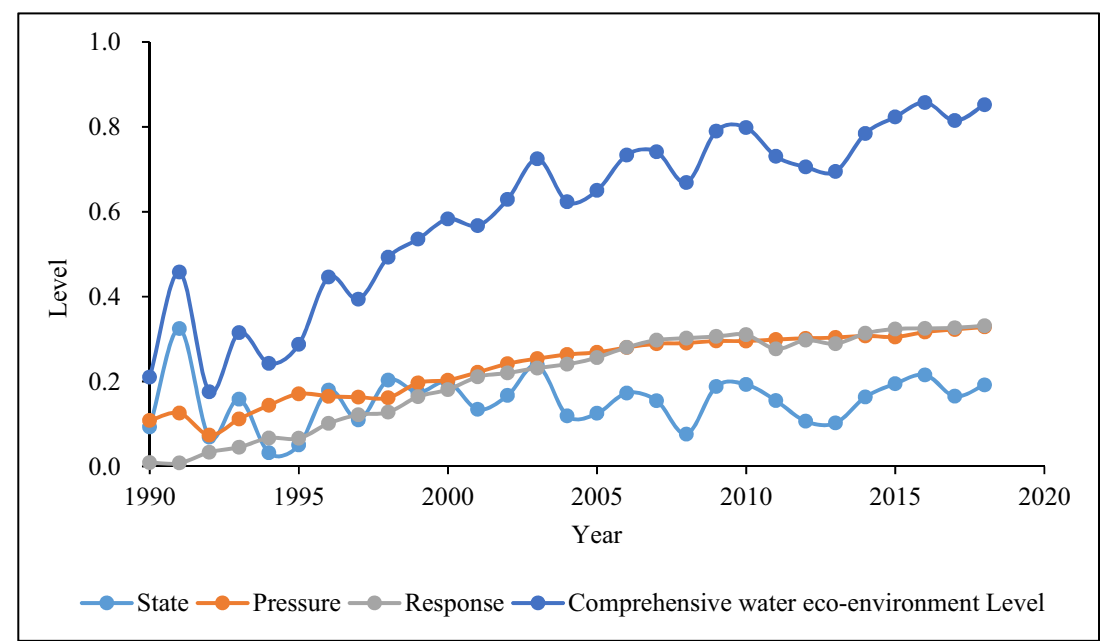


Fig. 4 Coupling coordination degree $(D)$ in Nanjing from 1990 to 2018

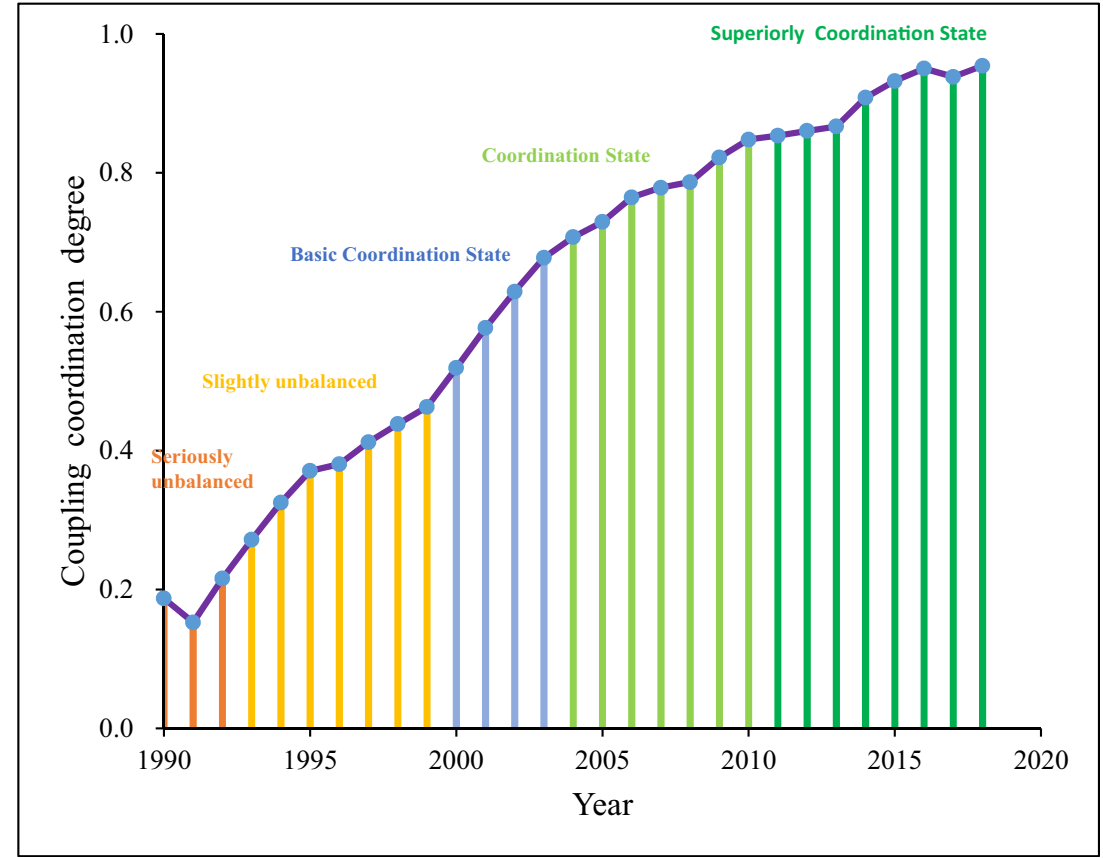

division in 2000 and 2002. The urban development and the relaxed regulation for migrant workers attracted population from the surrounding areas and neighboring provinces to Nanjing (Ma et al. 2016). The urbanization progress in this period was a typical government-oriented urbanization. Local governments operated land use rights to promote spatial urbanization. In addition, the local governments promoted population urbanization by encouraging more agricultural population to the city. In this period, economic urbanization and social urbanization shared the similar growth patterns. In economic urbanization subsystem, GDP per capita increased from 3,191 US\$ to 12,305 US\$, industrial output value per capita increased from 1,208 US\$ to 4,913 US\$, and total fixed asset investment per capita increased from 1,180 US\$ to 8,117
US\$. In the social urbanization subsystem, disposable income of urban residents per capita, consumption expenditure of urban residents per capita, and social consumer goods retail sales increased 3.44, 2.58, and 4.49 times in 2001-2010, respectively, which were directly related to economic development. The weights of these indicators were much larger than other indicators in social urbanization subsystem. In the meantime, unemployment, public transportation, and education also improved. Zhao et al. (2017) suggested that the interaction between economic and social issues was critical to global sustainability. For government-oriented urbanization, therefore, it is important to not only pay attention to the economic development brought about by population agglomeration and spatial expansion, but also use the disposable financial
Fig. 5 Comparison of the comprehensive urbanization and water environment indices in Nanjing from 1990 to 2018

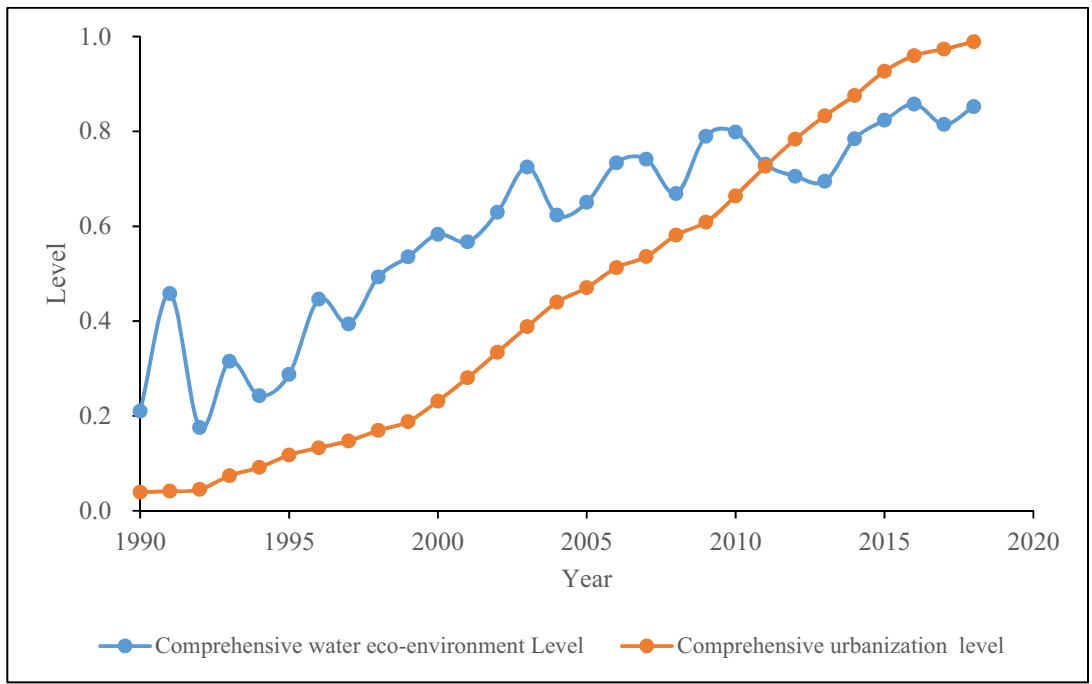


resources to improve the employment, social security, and public welfare to achieve sustainable urbanization.

In 2011-2018, driven by spatial and demographic urbanization, this period was featured with continuous economic growth and social progress but limited population agglomeration and spatial expansion. The economic urbanization index exceeded the spatial urbanization index in 2012 and demographic urbanization index in 2014, respectively (Fig. 2).

Compared with other large cities, for example, Shanghai and Beijing in China (He et al. 2017; Zhang et al. 2019a, b), the contribution and development speed of the urbanization subsystems in Nanjing are slightly different. One global urbanization study indicated that economic urbanization and social urbanization dominated the urbanization system (Zhao et al. 2017). CCD values in Singapore, Japan, and the Republic of Korea were higher than that in China. In Nanjing, demographic urbanization and spatial urbanization have made the largest contribution to the overall urbanization level from 1990 to 2018 (Fig. 2). It can be inferred that the population agglomeration and spatial expansion made the dominant contribution to the rapid development of urbanization in Nanjing. However, in Shanghai, economic indicators have taken into much larger account when measuring urbanization, while the contribution of demographic urbanization was the smallest during the period of 1990-2013 (He et al. 2017). In Beijing, social urbanization is considered to be the largest contributor to the overall urbanization level in the period of 2008-2017 (Zhang et al. 2019a, b). There are two reasons for the differences. First, due to the advantageous economic location in Shanghai and political policy in Beijing, the attractiveness and development speed of economy, medical service, and education in these two cities were obviously larger than those in Nanjing. Second, urban population is influenced by both the population policy and the urbanization rate (Fang et al. 2019). Compared with Nanjing, both Beijing and Shanghai have implemented much stricter urban household regulation policies for migrants.

\section{Assessment of the WE subsystems}

The overall performance levels of the WE subsystems showed an upward trend with fluctuations (Fig. 3). Nanjing lies in a subtropical monsoon-climate area with large interannual variation in rainfall, which induces marked fluctuations in the WE state subsystem index. Similar findings have been reported in Beijing, Suzhou, and other cities in eastern China (Huang et al. 2019; Ji and Ni 2018). The annual rainfall in 1992 was only $885.2 \mathrm{~mm}$, and industrial water consumption (Y14) reached the peak, which resulted in that year being the one with the greatest pressure on the WE. The domestic daily water consumption per capita (Y11) was relatively high from 1996 to 1998 , which led to a decrease in the pressure index. Since 1999, the industrial and domestic water consumption and pressure on the WE have decreased over time. In 20102014, large-scale concentrated urban construction for the Asian Youth Olympic Games, the Youth Olympic Games, and the massive rainwater and sewage diversion project affected industrial water reuse and groundwater quality, consequently lowering the overall level of the response subsystem (Hu et al. 2018). After 2014, owing to the slowdown of concentrated urban construction and the improvement of water resource conservation, WE has improved considerably (Liu et al. 2015; Yang 2014).

\section{Coupling coordination state}

Similar to many cities, there is a dynamic and complex coordination coupling relationship between urbanization and WE systems in Nanjing. In the early stage of urbanization in Nanjing (1990-1992), although economic development was slow and the discharge of industrial wastewater was large, the WE lagged behind urbanization. Urbanization did not have a severe impact on the WE. With the continued advancement of urbanization (1993-1999), water resource consumption and water environment quality were largely affected by urbanization, and the negative effect of urbanization on the WE became apparent. At this stage, the rapid urbanization was at cost of WE, indicating a level of coordination coupling which belongs to the category of "WE lagged" (Zhao et al. 2016). From 2000 to 2010 , the impact of urbanization development on the WE increased dramatically and even regularly exceeded the threshold of the water resources carrying capacity in the city (Jiang et al. 2014). Simultaneously, WE also exerted a substantially constraining function on urbanization. Therefore, urbanization gradually exerted a role of optimizing and regulating water resources and water environment. Higher urbanization increased the reliance on water resources and the water environment, which prompted additional financial investment in the development and protection of the WE. During this stage, the development of urbanization had both negative and positive effects on WE ( $\mathrm{Li}$ et al. 2020). The state of coupling coordination between urbanization and WE changed from the basic coordination state to the coordination state. In 2011, the comprehensive urbanization index surpassed the comprehensive WE index (Fig. 5). In 2012, Nanjing successfully approved the National Water-Saving Society Construction Pilot. The surface water quality improved gradually, while the groundwater quality continued to worsen. Only $26.7 \%$ of the groundwater met the water quality standard in 2013. Although the rate improved markedly in 2014 (73\%) and 2015 (60\%), it fell again to below 35\% in 2017 and 2018 .

Same as other regions in China, the protection of water resources, particularly groundwater, should be reinforced further in Nanjing (Yang et al. 2013a, b; Yang et al. 2015). Despite the continued development of urbanization, the protection of the WE has been strengthened, and the pressure on 
the water environment has decreased gradually over the past years (Yang et al. 2012a, b). Thankfully, the conflict between urbanization development and the WE has gradually diminished, thus resulting in a coordinated and orderly development stage (Yang et al. 2013a, b).

Our findings have some important policy implications. For a more sustainable urbanization in Nanjing and other cities in China, the policy makers should improve the quality of urbanization by deemphasizing the spatial and demographic urbanization but promoting socioeconomic development and environmental protection ( $\mathrm{Lu}$ et al. 2020). More supports should also go to city resident consumption, employment, education and health, social security, and public welfare. Importantly, governments should balance the development between urbanization and water resources utilization, particularly after the COVID-19 pandemic (Yang et al. 2020). More supports are needed for developing water-saving, wastewater treatment, and water recycling technologies (Dong et al. 2020).

\section{Limitations and future research}

Similar to many studies, this study has several limitations, and corresponding future studies warrant further exploration. First, there are multiple sources of data for Nanjing's water resource and water environment. For example, the percentages of surface water quality that met the water functional area standards are provided by both Nanjing Water Resources Bulletin and Nanjing Statistical Yearbook. By comparing the water environment quality of Qinhuai River (Nanjing's Mother River) (Gao et al. 2019; Wu et al. 2017), this study selected data from the Nanjing Water Resources Bulletin. The future studies including more data sources can further improve the estimation of water environment. Second, because of the different WE indicator systems in various studies, it is probably difficult to compare our findings with published results. For instance, the water indicator system did not account for the compliance rate of surface water resource functional areas and groundwater in the study in Beijing (Zhang et al. 2019a, b). In the future, more comprehensive and standard urbanization index and the WE index system should be applied so that the findings can have a wide application for the sustainable development of urbanization and water environment. Third, detailed water quality parameters have not yet included in the current study due to the unavailability of groundwater or surface water quality parameters in Nanjing City Water Resources Bulletin. It is estimated that Jiangsu's industrial wastewater discharge reached 1,652.13 million tons in 2017 (Yu et al. 2021). $\mathrm{COD}$ and $\mathrm{NH}_{4}{ }^{+}-\mathrm{N}$ are the main industrial water pollutants, which have been listed as the restrictive indicators of water environment from the beginning of "Outline of the $11^{\text {th }}$ Five-Year Plan (FYP) for National Economic and Social
Development" (NDRC, 2007). With available data in the future, the concentrations of COD and $\mathrm{NH}_{4}{ }^{+}-\mathrm{N}$ in surface water or groundwater can be consider in the further studies.

\section{Conclusion}

Globally, the urban population growth and urban spatial expansion have placed increasing pressure on the water environment. Similar to many cities, Nanjing entered a stage of rapid urbanization development. In this context, the developed coupling model was used to reveal the dynamic relationship between urbanization and the WE in Nanjing from 1990 to 2018.

Over the past 30 years, the comprehensive urbanization index showed an obvious growing trend, while its subsystems had different contributions to the comprehensive urbanization in different periods. Before 2000, demographic urbanization took the lead in urbanization. From 2000 to 2010, spatial urbanization developed rapidly and made the largest contribution to the overall urbanization. After 2011, economic urbanization has developed rapidly, surpassed spatial and demographic urbanization in 2012 and 2014, and became the dominant contributor to urbanization development.

The comprehensive WE index showed an increasing tendency with some fluctuation over the study period. At the subsystem level, the WE state index fluctuated largely with a subtle increasing trend, while the pressure index and response indices demonstrated clearly increasing trends with some fluctuation. Although water resource conservation has received ever-increasing attention, more effective measures are still needed to protect water resource, particularly the groundwater.

The state of the coordination between urbanization and WE experienced a dynamic evolution, from an imbalanced low coupling toward a superiorly coordinated highly coupled stage. With effective measures for the sustainable utilization of water resources and regional economic development, urbanization can benefit the water resource reservation. The key is to recognize the dynamic coupling law of interactive relationship between urbanization and WE and implement the appropriate measures to minimize the negative impact of the urbanization on WE within the water carrying capacity in the region.

The results of this study serve as a solid knowledge base for improving water resources and achieving sustainable urban development in Nanjing and other cities sharing the similar challenges of balancing urbanization and water resource.

Author contribution Conceptualization, X.M. and H.Y.; investigation, N.L.; validation, H. Y.; project administration, X.M.; resources, N.L. and Y.L.; writing - original draft preparation, X.M. and N.L.; writingreview and editing, H.Y.; funding acquisition, X.M and H. Y. 
Funding This work was supported by the Natural Science Research Projects of the Jiangsu Higher Education Institution (Grant No.19KJB170002), the Research Foundation for Advanced Talents (Grant No. 921001), and the Open Research Fund Program of Jiangsu Key Laboratory of Atmospheric Environment Monitoring and Pollution Control (KHK1806), a project funded by the Priority Academic Program Development of Jiangsu Higher Education Institutions (PAPD).

Data availability All data generated or analyzed during the current study are presented in this article. Data supporting the findings are available from the corresponding author upon reasonable request.

\section{Declarations}

Ethics approval and consent to participate Not applicable.

Consent for publication Not applicable.

Conflict of interest The authors declare no competing interests.

\section{References}

Ai J, Feng L, Dong X, Zhu X, Li Y (2016) Exploring coupling coordination between urbanization and ecosystem quality (1985-2010): a case study from Lianyungang City, China. Front Earth Sci 10:527545

Ariken M, Zhang F, Liu K, Fang CL, Kung HT (2020) Coupling coordination analysis of urbanization and eco-environment in Yanqi Basin based on multi-source remote sensing data. Ecol Indic 114: 106331

Bao C, Chen XJ (2015) The driving effects of urbanization on economic growth and water use change in China: a provincial-level analysis in 1997-2011. J Geogr Sci 25:530-544

Bao C, Zou JJ (2017) Exploring the coupling and decoupling relationships between urbanization quality and water resources constraint intensity: spatiotemporal analysis for Northwest China. Sustainability 9(11):1960

Conrad E, Cassar L (2014) Decoupling economic growth and environmental degradation: reviewing progress to date in the small island state of Malta. Sustainability 6(10):6729-6750

Cui X, Fang C, Liu H, Liu X (2019) Assessing sustainability of urbanization by a coordinated development index for an UrbanizationResources-Environment complex system: a case study of Jing-JinJi region, China. Ecol Indic 96:83-391

Ding L, Zhao WT, Huang YL, Cheng SG, Liu C (2015) Research on the coupling coordination relationship between urbanization and the air environment: a case study of the area of Wuhan. Atmosphere 6(10): $1539-1558$

Dong S, Yin C, Chen X (2020) Toxicity-oriented water quality engineering. Front Environ Sci Eng 14:5. https://doi.org/10.1007/s11783020-1259-4

Eigenbrod F, Bell VA, Davies HN, Heinemeyer A, Armsworth PR, Gaston KJ (2011) The impact of projected increases in urbanization on ecosystem services. Proc Royal Soc B-biol Sci 278(1722):32013208

Fang CL, Bao C, Huang JC (2007) Management implications to water resources constraint force on socio-economic system in rapid urbanization: a case study of Hexi Corridor, NW China. Water Resour Manag 21:1613-1633

Fang CL, Cui XG, Li GD, Bao C, Wang ZB, Ma HT, Sun S, Liu HM, Luo K, Ren YY (2019) Modeling regional sustainable development scenarios using the urbanization and eco-environment coupler: case study of Beijing-Tianjin-Hebei urban agglomeration, China. Sci Total Environ 689(1):820-830

Gao YQ, Lai LJ, Yao M, Ma ZZ (2019) Water environment quality assessment based on normal cloud-fuzzy variable set evaluation model. J Coast Res 93:39-46

Hambling T, Weinstein P, Slaney D (2011) A review of frameworks for developing environmental health indicators for climate change and health. Int J Environ Res Public Health 8:2854-2875

Han H, Li H, Zhang K (2019a) Spatial-temporal coupling analysis of the coordination between urbanization and water ecosystem in the Yangtze River Economic Belt. Int J Environ Res Public Health 16(19):3757

Han H, Li HM, Zhang KZ (2019b) Urban water ecosystem health evaluation based on the improved fuzzy matter-element extension assessment model: case study from Zhengzhou City, China. Math Probl Eng 7502342

He JQ, Wang SJ, Liu YY, Ma HT, Liu QQ (2017) Examining the relationship between urbanization and the eco-environment using a coupling analysis: case study of Shanghai, China. Ecol Indic 77:185193

Hong JK, Zhong XY, Guo S, Liu GW, Shen GQP, Yu T (2019) Waterenergy nexus and its efficiency in China's construction industry: evidence from province-level data. Sustain Cities Soc 48:101557

Hou QX, Zhang Q, Huang GX, Liu C, Zhang Y (2020) Elevated manganese concentrations in shallow groundwater of various aquifers in a rapidly urbanized delta, south China[J]. Sci Total Environ 701: 134777

Hu MC, Zhang XQ, Siu YL, Li Y, Tanaka K, Yang H, Xu YP (2018) Flood mitigation by permeable pavements in Chinese sponge city construction. Water 10(2):172

Huang YL, Huang JL, Ervinia A, Duan SW, Kaushal SS (2018a) Land use and climate variability amplifies watershed nitrogen exports in coastal China. Ocean Coast Manag 104428

Huang GX, Zhang M, Liu CY, Li L, Chen Z (2018b) Heavy metal(loid)s and organic contaminants in groundwater in the Pearl River Delta that has undergone three decades of urbanization and industrialization: distributions, sources, and driving forces. Sci Total Environ 635:913-925

Huang Y, Qiu QQ, Sheng YH, Min XQ, Cao YW (2019) Exploring the relationship between urbanization and the eco-environment: a case study of Beijing. Sustainability 11(22):6298

Huang GX, Liu CY, Zhang Y et al (2020) Groundwater is important for the geochemical cycling of phosphorus in rapidly urbanized areas: a case study in the Pearl River Delta. Environ Pollut 260:114079

Illingworth V (1996) The Penguin dictionary of physics. Foreign Language Press, Beijing, pp 92-93

Ji TT, Ni LQ (2018) Temporal characteristics of the coupling relationship between urbanization and water resources environment in Suzhou. Yangtze River 49(21):49-55 (In Chinese)

Jia ZM, Cai YP, Chen Y, Zeng WH (2018) Regionalization of water environmental carrying capacity for supporting the sustainable water resources management and development in China. Resour Conserv Recycl 134:282-293

Jiang YY, Zhang R, Feng KB (2014) Analysis on coupling interaction between urbanization of Nanchang City and water resources environment. Yangtze River 45(14):17-21 (In Chinese)

Juma DW, Wang H, Li F (2014) Impacts of population growth and economic development on water quality of a lake: case study of Lake Victoria Kenya water. Environ Sci Pollut Res 21:5737-5746

Juwana I, Perera BJ, Muttil N (2010) A water sustainability index for West Java - part 2: refining the conceptual framework using Delphi technique. Water Sci Technol J Int Assoc Water Pollut Res 62(7): $1641-1652$

Li YF, Li Y, Zhou Y, Shi YL, Zhu XD (2012) Investigation of a coupling model of coordination between urbanization and the environment. J Environ Manag 98:127-133 
Li BJ, Chen DX, Wu SH, Zhou SL, Wang T, Chen H (2016) Spatiotemporal assessment of urbanization impacts on ecosystem services: case study of Nanjing city, China. Ecol Indic 71:416-427

Li JB, Huang XJ, Kwan MP, Yang H, Chuai XW (2018) The effect of urbanization on carbon dioxide emissions efficiency in the Yangtze River Delta, China. J Clean Prod 188:38-48

Li Y, Huang JJ, Hu MC, Yang H, Tanaka K (2020) Design of low impact development in the urban context considering hydrological performance and life-cycle cost. J Flood Risk Manag 13. https://doi.org/ $10.1111 / \mathrm{jfr} 3.12625$

Liao C (1999) Quantitative judgement and classification system for coordinated development of environment and economy. Trop Geogr 19(2):171-177

Liu XZ, Heilig GK, Chen JM, Heino M (2007) Interactions between economic growth and environmental quality in Shenzhen China's first special economic zone. Ecol Econ 62(3):559-570

Liu YB, Yao CS, Wang GX, Bao SM (2011) An integrated sustainable development approach to modeling the eco-environmental effects from urbanization. Ecol Indic 11(6):1599-1608

Liu XP, Ma L, Li X, Ai B, Li SY, He ZJ (2014) Simulating urban growth by integrating landscape expansion index (LEI) and cellular automata. Int J Geogr Inf Sci 28(1-2):148-163

Liu J, Kattel G, Arp HPH, Yang H (2015) Towards threshold-based management of freshwater ecosystems in the context of climate change. Ecol Model 318:265-274

Liu N, Liu C, Xia Y, Da B (2018a) Examining the coordination between urbanization and eco-environment using coupling and spatial analyses: a case study in China. Ecol Indic 93:1163-1175

Liu WJ, Jiao FC, Ren LJ, Xu XG, Wang JC, Wang X (2018b) Coupling coordination relationship between urbanization and atmospheric environment security in Jinan City. J Clean Prod 204(PT.1-1178):1-11

Liu XR, Sun T, Feng Q (2020) Dynamic spatial spillover effect of urbanization on environmental pollution in China considering the inertia characteristics of environmental pollution. Sustain Cities Soc 53: 101903

Locatelli L, Mark O, Mikkelsen PS, Arnbjerg-Nielsen K, Deletic A, Roldin M, Binning PJ (2017) Hydrologic impact of urbanization with extensive stormwater infiltration. J Hydrol 544:524-537

Lu QL, Yang H, Huang XJ, Chuai XW, Wu CY (2015) Multi-sectoral decomposition in decoupling industrial growth from carbon emissions in the developed Jiangsu Province, China. Energy 82:414-425

Lu Y, Huang Y, Zeng S, Wang C (2020) Scenario-based assessment and multi-objective optimization of urban development plan with carrying capacity of water system. Front Environ Sci Eng 14:21. https:// doi.org/10.1007/s11783-019-1200-x

Luo K, Hu XB, He Q et al (2018) Impacts of rapid urbanization on the water quality and macroinvertebrate communities of streams: a case study in Liangjiang New Area, China. Sci Total Environ 621:16011614

Lyu R, Zhang J, Xu M, Li J (2018) Impacts of urbanization on ecosystem services and their temporal relations: a case study in Northern Ningxia, China. Land Use Policy 77:163-173

Ma HL, Chou NT, Wang L (2016) Dynamic coupling analysis of urbanization and water resource utilization systems in China. Sustainability 8(11):1176

Ma XX, Wang LC, Yang H, Li N, Gong C (2020) Spatiotemporal analysis of water quality using multivariate statistical techniques and the water quality identification index for the Qinhuai River Basin, East China. Water 12. https://doi.org/10.3390/w12102764

Nanjing Hydrological and Water Resources Management Bureau of Jiangsu Province (NHWRM) (2019) Nanjing City Water Resources Bulletin (2000-2019). Nanjing Hydrological and Water Resources Management Bureau of Jiangsu Province, Nanjing

Nanjing Municipal Bureau Statistics(NMBS) (2019a) Statistical communiqué of Nanjing on National Economic and Social
Development (2007-2019). Nanjing Municipal Bureau Statistics, Nanjing

Nanjing Municipal Bureau Statistics (NMBS) (2019b) Statistical yearbook of Nanjing (1991-2019). Editorial Department of Statistical Yearbook of Nanjing, Nanjing, ( http://221.226.86.104/file/index. htm ) (2019-12-05)

National Bureau of Statistics (NBS) (2019) China city statistical yearbook (1991-2019). China Statistical Press, Beijing

Naubi I (2017) Ranking of Skudai river sub-watersheds from sustainability indices application of PROMETHEE method. Int J Geomate 12(29):124-131

National Development and Reform Commission (NDRC) (2007) Outline of China's 11th five-year economic and social development program. Available online: http://ghs.ndrc.gov.cn/zttp/ghjd/quanwen/ (accessed on 12 September 2007). (2020-05-15)

Neri AC, Dupin P, Sanchez LE (2016) A pressure-state-response approach to cumulative impact assessment. J Clean Prod 126:288-298

Rasul G, Sharma B (2016) The nexus approach to water-energy-food security: an option for adaptation to climate change. Clim Pol 16: 682-702

Ren LJ, Cui EQ, Sun HY (2014) Temporal and spatial variations in the relationship between urbanization and water quality. Environ Sci Pollut Res 21(23):13646-13655

Shilling F, Khan A, Juricich R, Fong V (2013) Using indicators to measure water resources sustainability in California. World Environmental and Water Resources Congress, Cincinnati, pp $2708-2715$

Singhal DC, Joshi H, Mishra S (2015) Assessment of ground water sustainability for a subtropical town in ganga plain: a case study from North-India. J Groundwater Res 3(4/1):27-43

Srinivasan V, Seto KC, Emerson R, Gorelick SM (2013) The impact of urbanization on water vulnerability: a coupled human-environment system approach for Chennai, India. Glob Environ Chang 23:229 239

Tchakonte S, Ajeagah GA, Camara AI, Diomande D, Tchatcho NLN, Ngassam P (2015) Impact of urbanization on aquatic insect assemblages in the coastal zone of Cameroon: the use of biotraits and indicator taxa to assess environmental pollution. Hydrobiologia 755(1):123-144

United Nations (2018) World urbanization prospects. https://population. un.org/wup/. (2020-03-05)

United Nations (n.d.). $68 \%$ of the world population projected to live in urban areas by 2050, says UN. https://www.un.org/development/ desa/en/news/population/2018-revision-of-world-urbanizationprospects.html. (2020-03-05)

Wada Y, Bierkens MFP (2014) Sustainability of global water use: past reconstruction and future projections. Environ Res Lett 9(10): 104003

Wang Y (2020) Urban land and sustainable resource use: unpacking the countervailing effects of urbanization on water use in China, 19902014. Land Use Policy 90:104307

Wang SJ, Ma H, Zhao YB (2014) Exploring the relationship between urbanization and the eco-environment-a case study of BeijingTianjin-Hebei region. Ecol Indic 45:171-183

Wang JY, Wang SJ, Li SJ, Feng KS (2019a) Coupling analysis of urbanization and energy-environment efficiency: evidence from Guangdong province. Appl Energy 254:113650

Wang Q, Li SQ, Li RR (2019b) Evaluating water resource sustainability in Beijing, China: combining PSR model and matter-element extension method. J Clean Prod 206:171-179

Wen YR, Schoups G, Nick VDG (2017) Organic pollution of rivers: combined threats of urbanization, livestock farming and global climate change. Sci Rep 7:1-9

World Health Organization (WHO). Drinking-water. 2019. https://www. who.int/news-room/fadetail/detail/drinking-water. (2020-03-05) 
Wu CY, Huang XJ, Yang H, Lu QL, Xu GL, Li L, Li JB (2015) Embodied carbon emissions of foreign trade under the global financial crisis: a case study of Jiangsu province, China. J Renew Sustain Energy 7(4). https://doi.org/10.1063/1.4926803

Wu PB, Yin AJ, Yang XH, Zhang H, Fan M, Gao C (2017) Toxic elements in the stream sediments of an urbanized basin, Eastern China: urbanization greatly elevates their adverse biological effects. Environ Monit Assess 189(4):167-167

Xiao R, Lin M, Fei XF, Li YS, Zhang ZH, Meng QX (2020) Exploring the interactive coercing relationship between urbanization and ecosystem service value in the Shanghai-Hangzhou Bay Metropolitan Region. J Clean Prod 253:119803

Xu C, Wang S, Zhou Y, Wang L, Liu W (2016) A comprehensive quantitative evaluation of new sustainable urbanization level in 20 Chinese urban agglomerations. Sustainability 8:91

Yang H (2014) China must continue the momentum of green law. Nature 509:535-535

Yang H, Wright JA, Gundry SW (2012a) Boost water safety in rural China. Nature 484(7394):318-318

Yang H, Xie P, Ni LY, Flower RJ (2012b) Pollution in the Yangtze. Science 337:410-410

Yang H, Flower RJ, Thompson JR (2013a) China's new leaders offer green hope. Nature 493(7431):163-163

Yang H, Flower RJ, Thompson JR (2013b) Sustaining China's water resources. Science 339(6116):141-141

Yang H, Huang X, Thompson JR, Flower RJ (2015) Enforcement key to China's environment. Science 347(6224):834-835

Yang H, Xia J, Thompson JR, Flower RJ (2017) Urban construction and demolition waste and landfill failure in Shenzhen, China. Waste Manag 63:393-396. https://doi.org/10.1016/j. wasman.2017.01.026

Yang H, Ma M, Thompson JR, Flower RJ (2018) Waste management, informal recycling, environmental pollution and public health. J Epidemiol Community Health 72:237-243

Yang H, Ma M, Flower RJ, Thompson JR (2020) Protect the giant ibis through the pandemic. Science 369:929-929

Yao L, Li XL, Li Q, Wang JK (2019) Temporal and spatial changes in coupling and coordinating degree of new urbanization and ecological-environmental stress in China. Sustainability 11(4): $1171-1186$
Yu Y, Tong Y, Tang W, Yuan YB, Chen Y (2018) Identifying spatiotemporal interactions between urbanization and eco-environment in the urban agglomeration in the middle reaches of the Yangtze River, China. Sustainability 10(2):290

Yu QW, Wu FP, Zhang ZF, Wan ZC, Shen JY, Zhang LN (2021) Technical inefficiency, abatement cost and substitutability of industrial water pollutants in Jiangsu province, China. J Clean Prod 280: 124260

Zhang FG, Huang GX, Hou QX, Liu CY, Zhang Y, Zhang Q (2019a) Groundwater quality in the Pearl River Delta after the rapid expansion of industrialization and urbanization: distributions, main impact indicators, and driving forces. J Hydrol 577C:124004

Zhang KZ, Shen JQ, He R, Fan BH, Han H (2019b) Dynamic analysis of the coupling coordination relationship between urbanization and water resource security and its obstacle factor. Int $\mathrm{J}$ Environ Res Public Health 16(23):4765

Zhao W, Zhu X, Sun X, Shu Y, Li Y (2015) Water quality changes in response to urban expansion: spatially varying relations and determinants. Environ Sci Pollut Res 22:16997-17011

Zhao Y, Wang S, Zhou C (2016) Understanding the relation between urbanization and the eco-environment in China's Yangtze River Delta using an improved EKC model and coupling analysis. Sci Total Environ 571:862-875

Zhao YB, Wang SJ, Ge YJ, Liu QQ, Liu XF (2017) The spatial differentiation of the coupling relationship between urbanization and the eco-environment in countries globally: a comprehensive assessment. Ecol Model 360:313-327

Zhou ZX, Li J, Zhang W (2016) Coupled urbanization and agricultural ecosystem services in Guanzhong-Tianshui Economic Zone. Environ Sci Pollut Res 23(15): 15407-15417

Zhou D, Tian Y, Jiang G (2018) Spatio-temporal investigation of the interactive relationship between urbanization and ecosystem services: case study of the Jingjinji urban agglomeration, China. Ecol Indic 95:152-164

Publisher's note Springer Nature remains neutral with regard to jurisdictional claims in published maps and institutional affiliations. 